\title{
ADVERTISING FEATURE
}

\section{Oral health}

- a shared

responsibility

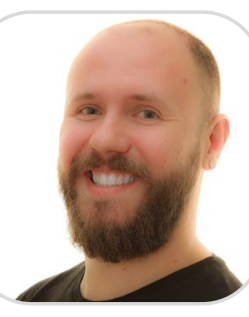

By Maxwell O'Neill, professional educator for Waterpik

The patient's role

As we well know, establishing and maintaining good dental hygiene requires more than an amazing professional team. The patient must understand the role they play in looking after their teeth and gums, and take appropriate responsibility for it. Whether during an active course of treatment or between routine check-ups, a lot of the work needs to be done at home.
Importance of accountability

It has been proven that home care is essential for successful outcomes in a wide range of treatments, from orthodontics ${ }^{1}$ to dental implant therapy. ${ }^{2}$ For instance, peri-implantitis is often found in patients with poor standards of oral hygiene post implant placement, ${ }^{3}$ which can jeopardise the survival of the implant.

In fact, effective oral hygiene is a prerequisite for any type of dental treatment and is discussed with patients before commencing a procedure. As such, it is vital that patients understand the importance of their role in maintaining the results achieved through treatment, if they are to enjoy the benefits for longer.

Even if not undergoing active treatment, patient compliance with oral health instructions can make a significant difference to their dental and general wellbeing. Without detailing all the links here, dental professionals will be well aware of the relationships between oral diseases like periodontitis and systemic health conditions, from cardiovascular disease to diabetes and even cancer. Patients, therefore, need to be accountable for their efforts in maintaining adequate oral hygiene at home, between practice visits.

How to improve engagement This all starts with patient education. If individuals appreciate the need for oral health, they are more likely to invest in looking after their teeth and gums. Communicating the right messages in the right ways often comes down to the patient-practitioner relationship. As rapport is developed and clinicians get to know their patients, they will be better able to transfer information in a way that their patient will listen to and understand. This might be something as simple as using a life 
event in the patient's life, like a big birthday or a family member's wedding, to motivate them to improve the health and aesthetics of their smile. Alternatively, it might help to use different language, analogies or visual aids to improve their comprehension.

Equally, it is beneficial to find a way of keeping patients engaged with their oral hygiene between appointments. Even those with the very best intentions may find their motivation waning over time - especially if we're all still staying indoors more than we would like to! Effective practice marketing can help substantially. Getting the oral health messages out there via popular channels like social media, emails or text messages, can provide the reminders patients need to stay on track.

\section{Getting the nation involved}

While reaching out to patients, why not use this year's National Smile Month (17 May-17

\section{'It has been proven that home care is essential for successful outcomes in a wide range of treatments, from orthodontics to dental implant therapy.'}

June 2021) to really stimulate patients and incite action? The 2021 campaign offers plenty of virtual ideas to get people involved and raise awareness of the importance of oral hygiene. Patients can join the Great British Brushathon, write a poem to spread the word or share their smile through a quick selfie on social media \#SmileMonth. There's also the Sugar Swap Challenge, which highlights the links between diet and oral/general health, and Dental Buddy - which is perfect to teach young children the basics of good dental care at home.

However your practice does it, National Smile Month is a great campaign to get patients engaged with their oral health, particularly if they haven't attended an appointment for a while.

\section{Enhancing homecare routines}

Once patients appreciate the importance of good oral hygiene, they need to know how to achieve it. This means providing tailored information on everything from brushing technique to fluoride content of toothpaste, as well as details of a balanced diet, regular exercise and adequate hydration. A part of the dental routine that many patients still forego is interdental cleaning, which often requires particular attention to encourage them to improve home care regimes.

Recommending an easy-to-use solution that has been clinically proven is often key. The Waterpik Water Flosser, for example, is a great alternative for people who find string floss difficult or uncomfortable to use. The solution is actually more effective than both string floss and interdental brushes for improving gingival health. ${ }^{4,5}$ Plus, with an array of models and tips available, there is an ideal product to suit every patient, including those with crowns and bridges, orthodontic appliances, dental implants or periodontal pocketing.

\section{A joint effort}

While dental professionals have a duty of care to help patients achieve and maintain good oral health, patients must appreciate they alone are responsible for their home care routine. If they are to optimise their oral and general wellbeing, a joint effort is essential.

For more information on Waterpik products visit www.waterpik.co.uk. Waterpik products are available from Amazon, Asda, Costco UK, Argos, Boots, Superdrug online and in stores across the UK and Ireland.

Book a free Waterpik professional Lunch and Learn for one hour of verifiable CPD and a free Waterpik Water Flosser - available either face to face or as a webinar - at www.waterpik.co.uk/professional/ lunch-learn/.

\section{References}

1. Levin R. How home care is essential to ensuring successful orthodontic treatment outcomes. Dent Today 2004; 23: 60-61.

2. Silverstein L H, Kurtzman G M. Oral hygiene and maintenance of dental implants. Dent Today 2006; 25: 70-75; quiz 75.

3. Charyeva O, Altynbekov K, Zhartybaev R, Sabdanaliev A. Long-term dental implant success and survival--a clinical study after an observation period up to 6 years. Swed Dent J 2012; 36: 1-6.

4. Lyle D M. Relevance of the water flosser: 50 years of data. Compend Contin Educ Dent 2012; 33: 278-280, 282. Available at: https://www.aegisdentalnetwork.com/ cced/2012/04/relevance-of-the-waterflosser-50-years-of-data (accessed 1 September 2020).

5. Goyal C R, Lyle D M, Qaqish J G, Schuller $R$. Evaluation of the plaque removal efficacy of a water flosser compared to string floss in adults after a single use. J Clin Dent 2013; 24: 37-42. 